\title{
Ensino de Química para deficientes visuais: uma síntese de estudos desenvolvidos em uma universidade do estado de São Paulo
}

\section{Enseñanza de la química para estudiantes con discapacidad visual: una síntesis de estudios desarrollados en una universidad del Estado de São Paulo}

\author{
Marina Lima Guedes Geraldo (marina.geraldo@hotmail.com) \\ Departamento de Ciências da Natureza, Matemática e Educação da Universidade Federal de São Carlos, \\ Campus Araras, SP, Brasil \\ Estéfano Visconde Veraszto (estefanovv@cca.ufscar.br) \\ Departamento de Ciências da Natureza, Matemática e Educação da Universidade Federal de São Carlos, \\ Campus Araras, SP, Brasil
}

Ana Carolina Anunciato Franco de Camargo (anaanunciatof@outlook.com) Centro Universitário Internacional, Uninter

Resumo: Devido a alterações em diretrizes educacionais e legislações, a presença de alunos deficientes em salas de aulas regulares aumentou. Os alunos deficientes visuais acabam excluídos pois o ensino está tradicionalmente pautado em padrões visuais. Algumas pesquisas foram desenvolvidas na Universidade Federal de São Carlos, no Campus de Araras, visando criar alternativas de ensino inclusivo de Química que abrangessem estes alunos. Assim, o seguinte trabalho foi proposto com o intuito de compreender como o ensino de deficientes visuais no âmbito da química tem sido realizado nos últimos anos. Para isso, foram utilizadas técnicas de Análise Textual Discursiva com o apoio do software NVivo. As categorias de análise criadas permitiram compreender como os autores entendem pontos cruciais no processo de inclusão, como a capacidade dos alunos deficientes visuais de aprenderem conceitos químicos. Enquanto alguns trabalhos consistiam em estudos teóricos que permitiram uma melhor compreensão de como a química tem sido ensinada em contextos reais de educação e quais as maiores dificuldades encontradas, outros trataram especificamente do desenvolvimento de atividades de ensino. Constatou-se uma lacuna no que se refere ao ensino de química para alunos com deficiência visual e um distanciamento entre a pesquisa científica e a educação básica brasileira.

Palavras-chave: educação inclusiva; deficiência visual; conceitualização em química.

Resumen: Gracias a los cambios en las pautas educativas y la legislación, ha aumentado la presencia de estudiantes discapacitados en las aulas regulares. Los estudiantes con discapacidad visual terminan excluidos porque la enseñanza se basa tradicionalmente en estándares visuales. Algunas investigaciones se realizaron en la Universidad Federal de São Carlos, en el Campus Araras, con el objetivo de crear alternativas de enseñanza de la Química, en una perspectiva inclusiva, buscando servir a estos estudiantes. Así, se propuso el siguiente trabajo para comprender cómo la enseñanza de las personas con discapacidad visual, en el campo de la química, se ha 
logrado en los últimos años. Para eso, se utilizaron técnicas de Análisis Textual Discursivo con el apoyo del software NVivo. Las categorías de análisis creadas nos permitieron comprender cómo los autores entienden los puntos cruciales en el proceso de inclusión, como la capacidad de los estudiantes con discapacidad visual para aprender conceptos químicos. Mientras que algunos trabajos consistieron en estudios teóricos que permitieron comprender mejor cómo se ha enseñado la química en contextos educativos reales y cuáles son las mayores dificultades encontradas, otros se ocuparon específicamente del desarrollo de actividades docentes. Al final, el estudio mostró una brecha con respecto a la enseñanza de química a estudiantes con discapacidad visual y una y una separación entre la investigación científica y la educación básica brasileña.

Palabras-clave: educación inclusiva; discapacidad visual; conceptualización en química.

\section{INTRODUÇÃO}

A demanda por educação inclusiva torna-se mais expressiva a cada dia, e ressalta a importância de romper padrões homogeneizadores ainda presentes nas salas de aulas. Para isso a escola regular deve ser repensada para atender às necessidades dos alunos, pois apenas a sua presença não garante a inclusão.

O ensino de conceitos de ciências da natureza para alunos deficientes visuais (DV), e mais especificamente os da área de química, se caracterizam como parte dos desafios que integram a educação inclusiva visto que os modelos tradicionais de ensino estão pautados em padrões visuais. Essa postura faz com que o aluno com deficiência visual seja ignorado, não considerando as diferenças de percepção no processo de ensino-aprendizagem quando comparados a alunos videntes. Além disso, as atividades de ensino inclusivas devem ser planejadas para todos os alunos, independente de possuírem deficiências visuais ou não, o que beneficia a todos os alunos da sala.

Muito professores, tanto em formação inicial quanto continuada, revelam um forte sentimento de insegurança no que se refere ao ensino deste alunado. Neste sentido, alunos de graduação e pós-graduação da Universidade Federal de São Carlos, no Campus de Araras, realizaram algumas pesquisas com o intuito de criar alternativas de ensino inclusivo de química que abrangesse alunos DV, além de estudos teóricos que permitissem traçar um panorama de como o ensino de DV tem sido realizado em contextos reais.

A presente pesquisa teve como objetivo dar continuidade a estes trabalhos ao propor uma análise de suas percepções, fragilidades e potencialidades. Assim, buscou- 
se ressaltar como as pesquisas voltadas ao ensino de DV têm sido realizadas nos últimos anos, e identificar seus aspectos positivos, suas fragilidades, e possíveis lacunas.

\section{METODOLOGIA}

Para a análise dos trabalhos foram utilizadas técnicas de Análise Textual Discursiva (MORAES; GALIAZZI, 2016). Para isso, os seguintes critérios foram seguidos: [a] unitarização ou desmontagem dos textos, onde foram examinados detalhes das pesquisas, buscando unidades que os constituem e que se referem aos fenômenos estudados; [b] estabelecimento de relações, iniciando o processo de categorização e construção de relações entre as unidades base, congregando conjuntos a partir de elementos próximos; [c] captação do novo emergente, que se deu a partir do resultado da análise das etapas anteriores, na busca por compreender os trabalhos analisados em sua totalidade; [d] a crítica e validação a partir da constituição de um metatexto; e [e] processo auto organizado, buscando resultados finais criativos e originais.

Os trabalhos que serviram como corpus de análise (Quadro 1) compreenderam tanto o desenvolvimento de alternativas de ensino inclusivo quanto estudos teóricos que mostraram como o ensino de Química vem sendo realizado em contextos reais.

Quadro 1 - Pesquisas desenvolvidas na área que serviram como corpus de análise

\begin{tabular}{|c|c|c|c|}
\hline $\bar{C}$ & 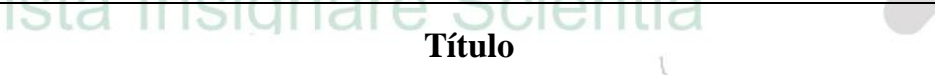 & Referência & Situação \\
\hline 1 & $\begin{array}{l}\text { Revisão Bibliográfica sobre metodologias utilizadas para ensinar } \\
\text { conceitos de química orgânica para alunos com deficiência visual }\end{array}$ & $\begin{array}{l}\text { BICHOFF, } \\
2017\end{array}$ & \multirow{4}{*}{$\begin{array}{l}\text { Monografia de } \\
\text { conclusão de } \\
\text { curso } \\
\text { concluída. }\end{array}$} \\
\hline 2 & $\begin{array}{l}\text { Substâncias odorantes como auxiliares na identificação de grupos } \\
\text { funcionais orgânicos: uma proposta de ensino de química para } \\
\text { alunos com deficiência visual }\end{array}$ & $\begin{array}{l}\text { REATO, } \\
2017\end{array}$ & \\
\hline 3 & $\begin{array}{c}\text { Proposta de material didático acessível para o ensino de } \\
\text { bioquímica a alunos com deficiência visual }\end{array}$ & $\begin{array}{l}\text { ZAMBONE, } \\
2017\end{array}$ & \\
\hline 4 & $\begin{array}{l}\text { Ensino de Química e a trajetória escolar de deficientes visuais: } \\
\text { dificuldades e desafios }\end{array}$ & $\begin{array}{l}\text { SANTOS, } \\
2018 \mathrm{a}\end{array}$ & \\
\hline 5 & $\begin{array}{c}\text { O processo de aprendizagem de conceitos químicos por alunos } \\
\text { com deficiência visual }\end{array}$ & $\begin{array}{l}\text { MOLENA, } \\
2018\end{array}$ & $\begin{array}{l}\text { Mestrado } \\
\text { concluído }\end{array}$ \\
\hline 6 & $\begin{array}{c}\text { Ensino de química e Literatura de Cordel: desenvolvimento e } \\
\text { aplicação de livro paradidático sobre química orgânica para } \\
\text { alunos deficientes visuais }\end{array}$ & $\begin{array}{l}\text { SANTOS, } \\
2019\end{array}$ & $\begin{array}{l}\text { Mestrado em } \\
\text { andamento }\end{array}$ \\
\hline 7 & $\begin{array}{c}\text { A Química na perspectiva de adultos cegos do centro dia de } \\
\text { referência de atendimento para pessoas com deficiência de Rio } \\
\text { Claro }\end{array}$ & $\begin{array}{l}\text { SANTOS, } \\
2018 b\end{array}$ & $\begin{array}{l}\text { Iniciação } \\
\text { Científica } \\
\text { concluída }\end{array}$ \\
\hline
\end{tabular}


Por se tratar de uma pesquisa com grande volume de dados foi utilizado o software NVivo, o qual tem sido um dos mais utilizados no meio acadêmico brasileiro (LAGE, 2011). Este software permite criar "nós", que agrupam materiais sobre temas e tópicos específicos, e foi utilizado visando simplificar a organização dos dados.

A investigação dos trabalhos contou com a construção de categorias préestabelecidas, que permitiram facilitar o processo de categorização. Resumidamente, estas categorias são: Percepção de inclusão; Referenciais teóricos (que fundamentam as pesquisas); Aporte legal (que fundamentam as pesquisas); Metodologia; Estratégias de ensino.

Estas categorias passaram por revisão, e a categoria que tratava sobre as percepções de inclusão foi dividida em subcategorias: Capacidade; Cognição e Percepção; Compensação por outros sentidos; Mediação Social; Formação de Professores; Recursos alternativos de apoio e Dificuldades para a inclusão. Trabalhos desenvolvidos previamente que visavam compreender como professores em formação de ciências exatas entendem a possibilidade de atuação de cegos congênitos em atividades científicas (VERASZTO; CAMARGO; CAMARGO; 2016; VERASZTO et. al.; 2014, 2018a; 2018b; 2019) nortearam a criação dessas subcategorias.

\section{RESULTADOS E DISCUSSÃO}

A categoria Capacidade agrupou colocações nos trabalhos analisados que mostram o posicionamento dos autores no que se refere a capacidade dos alunos com DV aprenderem fenômenos e conceitos químicos.

T1: Os alunos cegos possuem o mesmo potencial de aprendizagem, podendo demonstrar um desempenho escolar equivalente ou até mesmo superior aos alunos videntes, mediante condições e recursos adequados [...]

T3: Os alunos deficientes visuais estão aptos para aprender qualquer conteúdo ensinado [...].

T4: Fica claro, também, que os deficientes visuais são capazes sim de aprender como qualquer outro aluno [...]

T5: [...] a visão não é fator limitante para o processo de aprendizagem e desenvolvimento dos alunos com DV, já que a aprendizagem de conceitos não fica comprometida, desde que os 
outros aspectos sejam adequados para atender as necessidades especiais desses alunos.

A maioria dos trabalhos coloca que a deficiência visual não é um impeditivo no que se refere à capacidade de o aluno aprender os conteúdos científicos, e levam em consideração que o fator determinante nesse sentido é, na verdade, as condições educativas fornecidas ao indivíduo. Porém, T2 chamou a atenção ao tratar sobre a compreensão de conceitos abstratos pelo aluno DV, os quais são muito recorrentes na química.

T2: Se para os alunos normovisuais e sem nenhum tipo de necessidade educacional especial a compreensão de determinados conceitos já é difícil, dada sua abstração, essa dificuldade se acentua muito para os estudantes com deficiência visual.

$\mathrm{O}$ ensino de conceitos abstratos está fortemente relacionado às representações externas, através de livros, projeções e desenhos na lousa. Camargo (2012) aponta que a dificuldade de ensinar estes conceitos está relacionada à dificuldade comunicacional, já que estes significados geralmente são vinculados às representações não visuais. $O$ mesmo autor afirma que quando desvinculados de tal referencial esses significados se tornam acessíveis ao aluno DV, e pelo fato de não terem acesso a representações visuais, os alunos cegos congênitos podem ter uma vantagem no entendimento desses fenômenos.

Em Cognição e Percepção pode-se avaliar como os autores entendiam o desenvolvimento cognitivo e sua relação com os sentidos sensoriais. Assim, procurouse compreender como os autores relacionavam a deficiência visual e a capacidade de aprendizagem destes alunos. Primeiramente serão colocados trechos que não consideram a deficiência visual como um fator limitante na aprendizagem de fenômenos químicos:

T1: A deficiência visual não interfere na capacidade intelectual e cognitiva.

T4: Deficientes visuais e videntes possuem processos cognitivos diferentes, e tal distinção ocorre porque os deficientes visuais possuem percepção própria.

T5: [...] a visão não é fator limitante para o processo de aprendizagem e desenvolvimento dos alunos com $D V$, já que a aprendizagem de conceitos não fica comprometida, desde que os outros aspectos sejam adequados para atender as necessidades especiais desses alunos. 
Como apontado, estas pesquisas apontam que os alunos DV podem aprender qualquer conceito através da utilização de outros sentidos. A concepção da deficiência visual como um fator limitante, portanto, deve ser superada.

T3: Caso não exista um direcionamento adequado logo nos primeiros anos de vida à criança com deficiência visual, pode desenvolver um atraso nos desenvolvimentos cognitivo, físico e psicossocial.

O trecho acima destaca a importância da criança DV receber estímulos desde os anos iniciais, e coloca isso como um fator determinante no seu desenvolvimento cognitivo.

A categoria Compensação Por Outros Sentidos reuniu trabalhos que entendem ser possível a cegueira e a deficiência visual serem compensadas por outros sentidos como o tato e a audição.

T1: [...] considerando que é necessária a utilização de recursos alternativos que explorem os demais sentidos, como por exemplo, a sensibilidade tátil, altamente apurada por um deficiente visual, para auxiliá-lo na compreensão de conteúdos específicos desta disciplina.

T2: Utilizar a vantagem da exacerbação do sentido do olfato na pessoa com deficiência visual como facilitador do seu processo de aprendizagem.

Os autores se referem ao tato e a audição como sentidos mais desenvolvidos nos alunos DV. Vigotski coloca que não há compensação biológica no caso de uma falha em um dos órgãos do sentido, e, assim, o tato e a audição jamais poderão ensinar o cego a ver. Na verdade, o que acontece é uma compensação sócio-psicológica (VIGOTSKI, 1997), visto que os outros sentidos são mais utilizados por estes indivíduos.

A categoria Mediação Social reuniu passagens dos trabalhos que refletem a ideia de que a aprendizagem de conceitos científicos em uma perspectiva inclusiva pode ser possibilitada através da atuação do meio social. Neste sentido, mostram a importância da participação de professores, gestão escolar, familiares e a sociedade de maneira geral.

T1: Três elementos são fundamentais neste processo inclusivo no ambiente escolar: o sujeito incluído, o professor e a família.

T1: [...] todos os envolvidos no processo educacional devem ter uma preparação para poderem contribuir de forma significativa.

T4: [...] para que a inclusão seja realmente efetiva em ambiente escolar é necessário que ocorra um trabalho em conjunto com a gestão, com os docentes (especializados e professores de classe 
regular), familiares e também de uma maior fiscalização das leis que regem a inclusão.

T3: [...] é importante que professores educadores, a comunidade e a escola estejam mobilizados e trabalhando de maneira conjunta para que esta mudança aconteça.

Estes trabalhos apontam como relevante que haja uma parceria entre a gestão escolar, os professores, a família e a comunidade para que se possa vencer este desafio.

T1 citou a importância do apoio emocional a pessoa com deficiência:

T1: O apoio emocional pode ser uma ferramenta valiosa de estreitamento na inclusão social da pessoa com deficiência. Além desse apoio, a informação e a orientação adequadas contribuem para a inclusão do aluno com deficiência visual.

A educação pode ser vista como uma rota de fuga das adversidades, e é importante que famílias e crianças que vivam em situação de estresse recebam ajuda e apoio emocional pois essas condições podem ser desfavoráveis a aprendizagem.

A importância das legislações e políticas públicas também foram apontadas em alguns trabalhos:

T2: É obrigação do Estado, elaborar políticas públicas, sobretudo na área da Educação, que visem o tratamento igualitário de todas as pessoas, independentemente de suas condições socioculturais ou econômicas.

T2: O estado possui um papel importante diante das questões que estabelecem o deficiente como um membro efetivo na sociedade.

T5: Para que a educação inclusiva se torne efetiva, entende-se que é necessária [...] a elaboração e aplicação de políticas públicas, pois só assim os estudantes terão acesso à educação de qualidade.

T5: Esse processo depende também da elaboração e aplicação de políticas públicas adequadas para garantir a igualdade de direitos.

Neste sentido, ressalta-se que a educação inclusiva precisa ser entendida como um dever que deve ser assumido e concretizado pelo Estado.

A importância da escola e sua organização para promover a inclusão também são aspectos discutidos nos trabalhos analisados:

T2: Para as escolas regulares se adaptarem às necessidades específicas de cada aluno, é relevante cultivar um ambiente inclusivo, combatendo, através da pluralidade, todo e qualquer tipo de preconceito ou exclusão da pessoa com deficiência, promovendo de forma igualitária o acesso à educação. 
T3: [...] sendo a escola o local social em que se promovem as estratégias educacionais para o indivíduo, [...] ela tem a função formadora do seu cognitivo elaborando através dos ensinamentos que promove as estruturas mentais dos mesmos.

T5: $O$ ambiente escolar precisa estimular e aumentar a participação de todos, buscando a equidade, e isso é possível por meio da compensação das diferenças, atendendo as necessidades da maioria dos alunos, sejam elas com deficiência ou NEE.

T7: É esse o papel que a escola deve ter. Deve ser acolhedora, deve estreitar laços familiares com os alunos, deve motivá-los. $O$ aluno precisa se identificar com a escola, precisa sentir-se valorizado, o protagonista, bem cuidado, construir laços de amizades com os outros estudantes e professores e assim se lembrar do seu período escolar na fase adulta com carinho e saudade [...]

É apontado a necessidade de a escola possuir estrutura para atender às diferenças individuais, respeitando as necessidades de todos os alunos, neste sentido, deve ser considerada mais do que um espaço físico, mas uma unidade social que possibilita o desenvolvimento do indivíduo na integralidade do seu ser.

Alguns trabalhos falaram especificamente sobre a importância da família durante a escolarização dos indivíduos:

T4: A família [...] será sempre o primeiro contato, a primeira relação entre o grupo social que o indivíduo irá ter e pertencer. Logo, tem um papel decisivo no desenvolvimento do sujeito, cooperando na edificação de sua personalidade, nas suas atitudes como cidadão, mesmo quando este chegar a fase adulta $[\ldots]$

T5: A família também possui papel importante no desenvolvimento da pessoa, influenciando também em sua personalidade, formação cultural e evolução social.

T7: A família possui um enorme papel no processo de desenvolvimento e na aprendizagem dos indivíduos. Atua como mediadora na interação do aluno com a sociedade e no processo de construção do conhecimento.

A família exerce grande influência no desenvolvimento do indivíduo, e o processo em direção a inclusão deve se iniciar muito antes de a criança ir para a escola, sendo decisivo para a construção da independência desses indivíduos.

O convívio de alunos com e sem deficiência foi um aspecto também citado:

T4: Na Educação especial na perspectiva Inclusiva, todos os estudantes precisam conviver juntos e realizar as atividades com o mesmo nível de cobrança condizentes com o da classe em que 
se encontram, e assim, ter as mesmas oportunidades de aprendizagem [...]

T7: Ter amigos durante o período escolar é de extrema importância não só para um bom convívio social, mas também para a aprendizagem.

Conviver em uma turma heterogênea possibilita aos alunos conviver com a diferença, o que se torna benéfico a todos.

O Atendimento Educacional Especializado foi citado em alguns trabalhos como uma forma de auxiliar no processo de aprendizagem do aluno deficiente.

T2: Dentre os programas criados pelo Brasil está o Atendimento Educacional Especial (AEE): uma forma de proporcionar ao aluno com deficiência maior acessibilidade ao ensino regular.

T2: O Atendimento Educacional Especial (AEE) foi a forma encontrada pelo Brasil para viabilizar uma educação inclusiva da pessoa com deficiência. Nesta proposta a adequação utiliza o AEE como um sistema complementar e proporciona ao aluno um complemento e não a substituição do ensino regular, no qual ele deve estar devidamente inserido, conforme sua deficiência.

T4: A presença de uma sala de recursos multifuncionais e de um professor de atendimento educacional especializado (AEE) faz com que aconteça um trabalho ainda mais significativo, pois o professor do AEE poderá fazer um estudo mais profundo de todos os alunos para assim planejar uma didática adequada aquele aluno.

T4: Assim é urgente a democratização desse sistema, e nesse sentido os serviços de apoio, professores especializados, desempenham uma importante função, podendo promover oficinas de braile para comunidade e para familiares [...]

T7: Entende-se a importância de instituições especializadas que quando utilizadas de acordo com a Constituição trazem grande benefício as pessoas com deficiência, porém é direito de todos estudarem em escolas regulares [...]

T7: Por isso a presença de uma sala de recursos multifuncionais $e$ de um professor de atendimento educacional especializado (AEE) faria com que ocorresse um trabalho ainda mais significativo nas escolas, porque o professor do AEE poderia auxiliar o professor da classe regular e ambos poderiam trabalhar juntos [...]

É importante ressaltar que os trabalhos que citam a importância da AEE sempre colocam esta como um complemento, ressaltando o direito de o aluno frequentar uma escolar regular. Além disso, o papel do professor especializado destaca-se ainda mais 
por possibilitar também a participação da família e da comunidade, aproximando e estreitando laços deficientes visuais.

T2: Em um modelo apresentado para o AEE, o aluno pode evoluir de acordo com suas habilidades e ser constantemente avaliado para buscar alternativas de otimizar a assistência do programa, sempre no caminho de encontrar o melhor jeito de fazer, seja de forma individual ou coletiva.

Esta passagem reproduz um equívoco quanto a proposta inclusiva ao colocar a necessidade de um diagnóstico para promover a inclusão de deficientes no ensino regular. A prática de exames, avaliações e classificações de crianças são tradicionalmente usadas para separar umas crianças das outras (MITTLER, 2003).

A importância do professor é citada diversas vezes nos trabalhos analisados, mostrando-se central ao auxiliar os alunos com DV no processo de ensinoaprendizagem, conforme apontado:

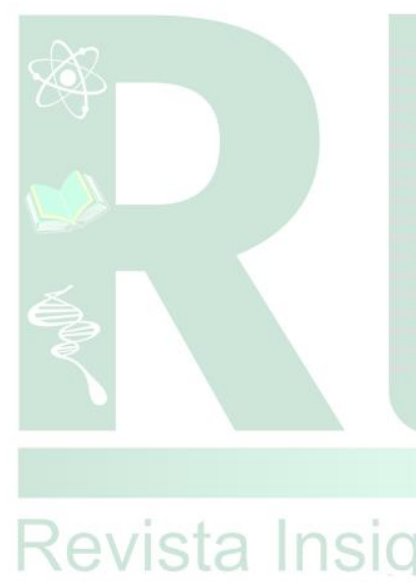

T2: A pessoa com necessidade educacional especial deve contar com um elo forte em seu aprendizado, que inclui o docente.

T3: [...] ]ensinar atendendo as diferenças não resulta em mudar a maneira de ensinar a criança com deficiência, mas sim de adotar uma nova proposta pedagógica integradora, a qual atenda as diferenças de todos os estudantes [...]

T4: [...] é necessário que o docente faça atividades visando atender todos os alunos, proporcionando um ambiente inclusivo, onde todos contenham acesso e condições de participar ativamente.

T5: [...] ]o professor desempenha papel importante no processo de ensino-aprendizagem, pois é preciso saber identificar no educando como ele é, age, pensa, fala e sente, se atentando ao referencial perceptual utilizado, que no caso do aluno com cegueira, não é a percepção visual.

T6: [...] o professor tem papel fundamental, já que ele é o intermediador, aquele que provoca e encoraja o aluno por meio de estratégias pedagógicas que visão melhorar situações de aprendizagem, moldando o conteúdo e as atividades de modo que o estudante o assimile em sua realidade.

T7: [...] o professor então tem papel fundamental, pois ele é o intermediador, aquele que desafia e encoraja o aluno por meio de estratégias pedagógicas que procuram melhorar situações de aprendizagem, moldando o conteúdo e as atividades de acordo com a realidade do estudante.

Mittler (2003) aponta que o papel do professor é realmente central para proporcionar a aprendizagem dos alunos, visto que as baixas expectativas destes em 
relação aos alunos podem fazer com a profecia do insucesso escolar seja cumprida. Os laços afetivos criados entre alunos e professores tem extrema importância, visto que esses alunos muitas vezes presenciam diariamente discórdias familiares, e outras experiências de tensão e perigo. Porém os professores por diversos motivos não conseguem se manter a par do que acontece na vida desses alunos fora da escola.

Partindo agora para o ensino de ciência, e mais especificamente o de química, para alunos deficientes visuais, algumas colocações foram feitas:

T4: Os docentes precisam ser capazes para viabilizar, por meio de uma comunicação apropriada, condições que beneficiem a realização dos cálculos que estão presentes no Ensino de Química/Ciências, por alunos com deficiência visual.

T7: Na escola é necessário para que a aprendizagem seja efetiva possibilitar a coleta de informações através dos demais sentidos, como a audição, o tato, o paladar e a o olfato que acabam se tornando canais que levarão até o cérebro informações.

Estes trabalhos destacam que as atividades realizadas em conjunto ao professor devem explorar os demais sentidos, e assim tornar-se acessível a todos.

A categoria Recursos Alternativos de Apoio identificou recursos e serviços que auxiliam no processo de ensino-aprendizagem do DV, favorecendo a autonomia e independência. Alguns dos trabalhos citaram o desenvolvimento de materiais multissensoriais, com grande potencial inclusivo por abranger as necessidades educacionais de todos os alunos.

T2: Encontraram-se na literatura diversos materiais aplicáveis na construção de modelos alternativos para utilização no ensino de Química para alunos com deficiência visual, sendo a aplicação de texturas uma alternativa facilitadora da compreensão por meio do tato.

T3: As tecnologias existentes hoje, como os recursos fornecidos pelos aparelhos eletrônicos e o acesso à internet, são ferramentas capazes de auxiliar nos processos de inclusão e então no crescimento social, a globalização da informação e a diminuição das diferenças, portanto podem e devem ser utilizadas nos processos de ensino-aprendizagem para os alunos com deficiência visual.

T3: Os materiais didáticos inclusivos podem ser utilizados como auxiliares no processo de ensino-aprendizagem, possibilitando uma maior aproximação dos alunos com o conteúdo, não só aqueles com necessidades especiais, mas também para os videntes e nas relações sociais existentes nas salas de aula.

T3: Como exemplo de recursos didáticos específicos para os alunos com deficiência visual, temos presentes nas salas de 
recursos das escolas, os modelos, mapas geográficos, políticos, históricos, livros falados, auxílio de vídeos e TV, além do grande auxílio da impressora Braille, scanners, e outras tecnologias disponíveis no mercado [...]

T3: [...] no caso dos alunos com deficiência visual, o livro didático (principal e muitas vezes única fonte de consulta dos alunos do ensino regular) não corresponde todas as necessidades dos alunos, e torna-se então necessário o desenvolvimento de novos materiais didáticos, que sejam inclusivos, como por exemplo, materiais auditivos, materiais didáticos táteis elou livros didáticos adaptados em braile [...]

T4: Já como tecnologias assistivas os professores podem utilizar: Programas de leitor de tela, linha Braile, Impressora braile, Optacon que é um aparelho portátil que ajuda o deficiente visual a ler um texto impresso em tinta, além de uma calculadora cientifica dentre outros recursos que ajudam no processo de inclusão [...]

T4: Hardwares e Softwares criados especialmente para deficientes visuais pode ser de grande ajuda.

T5: Com a utilização de metodologias adequadas e recursos especiais que utilizam os múltiplos sentidos perceptivos, os alunos podem participar do processo de ensino-aprendizagem efetivamente.

T6: Além do Braile, o professor pode também utilizar diferentes materiais didáticos táteis que podem ser feitos a partir de colagens de diversas estruturas dentre outras, explorando assim os outros sentidos [...]

T7: Além do Braile, o professor é livre também para usar diferentes materiais didáticos táteis que podem ser feitos a partir de colagens de diversas estruturas dentre outras maneiras, explorando assim os outros sentidos [...]

Alguns trabalhos apontaram especificamente a necessidade da utilização da do Braille, Sorobã, e mais especificamente na área da Química, a Grafia Química Braille:

T3: Existe hoje disponível pelo Ministério da Educação, por uma publicação a "Grafia Química Braille para uso no Brasil" que auxilia na representação de fórmulas, equações e símbolos químicos.

T4: O Sorobã é um aparelho de origem japonesa que possibilita que deficientes visuais façam operações matemáticas. E a falta desse instrumento pode causar prejuízos na aprendizagem do estudante deficiente visual em matérias como química, física e matemática que necessitam quase sempre de cálculos.

T4: Um dos recursos táteis que podem ser utilizado pelos cegos é o braile $[\ldots]$ 
T5: O Braile é o mais comum meio de aprendizagem de litura e escrita para cegos e deficientes visuais.

T5: O braile é um recurso especial que auxilia a pessoa com deficiência a ter acesso às informações escritas, seja no ambiente escolar ou em um outro local.

T5: Devido a necessidade de normatização das representações de Química, foi criada a "Grafia Química Braille para Uso no Brasil” (BRASIL, 2011), com o objetivo de garantir o acesso aos textos específicos da área, e após a alfabetização em braile, o aluno com DV poderá participar ativamente das aulas de Química [...]

Os recursos didáticos assumem uma importância ímpar na educação na educação de alunos DV, conferindo motivação para a aprendizagem e suprindo lacunas na aquisição de informação por essas crianças. Citados em alguns trechos dos trabalhos acima, esses materiais mostram um grande potencial inclusivo por atenderem as necessidades educacionais de todos os alunos, e devem ser trabalhados em contextos interativos e comuns a todos os alunos (CAMARGO, 2012a).

Alguns trabalhos indicaram pontos que tornam a educação inclusiva difícil de ser efetivada nas escolas regulares. Por isso foi criada a categoria Dificuldades para Inclusão, a qual cita aspectos como as barreiras comunicativas, a formação dos professores e a falta de investimentos em recursos tecnológicos.

T2: As dificuldades que o aluno com deficiência visual enfrenta em suas tentativas de inserção na sociedade são diversas, desde a busca por uma instituição de ensino que possua todos os recursos e equipamentos necessários para transpor a barreira de acesso à informação, passando pela tentativa de adequação ao ambiente escolar: docentes preparados, sala de recursos $e$ acessibilidade física, até o entrave pelo reconhecimento de suas capacidades intelectuais frente aos demais alunos, na maioria das vezes causada pela falta de estímulo aos sentidos remanescentes

T3: A carência de recursos didáticos especializados e pensados para os alunos com deficiência visual torna-se um grande desafio para a promoção da educação inclusiva.

T5: [...] ]algumas barreiras podem ser encontradas e a partir dos pressupostos de Camargo (2012) a comunicação é uma delas $[\ldots]$

T5: Um outro aspecto em que as escolas estão ultrapassadas é sobre a falta de investimentos em tecnologias, que são recursos com os quais os adolescentes estão acostumados a utilizar para acessar redes sociais e não sabem como esses instrumentos podem auxiliar no processo de aprendizagem de conceitos. 
A comunicação se refere ao compartilhamento de significados entre emissor e receptor sobre um determinado objeto, informação, mensagem ou ideia. Porém, o entendimento de determinados significados depende de entidades representadas inicialmente na consciência (CAMARGO, 2012a).

Outro aspecto apontado é a dependência de representações visuais nas aulas:

T4: Visto que muitas vezes a visão é o sentido mais utilizado dentro das salas de aula, e as aulas são sempre expositivas $e$ tradicionais.

T5: Um dos problemas do ensino de Química é a ênfase no aspecto da representação visual, não destacando os fenômenos presentes no ambiente.

T6: [...] a maioria das aulas são tradicionais e se apoiam na visão como sentido fundamental [...]

T7: [...] as maiores dificuldades no ensino da química estão em encontrar formas e meios de estimular nos alunos o interesse pela química. E também conseguir comunicação de informação de outra maneira sem ser visível.

Como citado anteriormente, a química contém muitos conceitos abstratos o qual estão fortemente relacionados a representações externas. Superar esse modelo de ensino tradicional tem se mostrado urgente para alcançar um desenvolvimento mais justo.

A forma de avaliação também é uma dificuldade citada no que diz respeito ao processo de inclusão.

T7:Um outro problema é a forma como os professores avaliam os alunos cegos ou deficientes.

O professor deve deixar de lado o caráter classificatório de notas e provas, e passar a avaliar o desenvolvimento das competências dos alunos, e sua capacidade de resolução de problemas.

Diversos apontamentos foram feitos sobre a falta de preparo dos professores e suas condições de trabalho como barreiras à inclusão:

T3: A inclusão de pessoas com deficiência visual nas salas de aulas regulares apresenta uma série de desafios, não apenas para os alunos que possuem uma série de dificuldades $e$ limitações, mas também para os professores, que muitas vezes não foram preparados e podem não estarem capacitados para participar deste trabalho inclusivo.

T4: E muitas vezes os professores como já foi dito aqui não estão preparados e não sabem como agir diante de um aluno deficiente visual. 
T4: Em suma, por meio desses dados percebe-se que uma das maiores dificuldades para a inclusão acontecer são os próprios professores que mal formados e esgotados devido as suas péssimas condições de trabalho culpam o aluno deficiente pelo fracasso escolar, não se preocupam em estreitar relações com este aluno, e não procuram entender os motivos de sua desmotivação, o mesmo é dito pela escola que também se mostra ausente.

T6: Existem muitos desafios a serem superados sendo um dos principais a falta de preparo dos professores, e [...] a falta de conhecimento desses docentes sobre educação inclusiva.

Não há como negar que as condições de trabalho dos professores se mostram desfavoráveis e desestimulantes. Porém, é importante que além de reconhecer as dificuldades enfrentadas por eles próprios, também se reconheçam como responsáveis desse processo de inclusão, promovendo estratégias para romper barreiras a participação de seus alunos (CARVALHO, 2011).

As potencialidade e fragilidades identificadas em cada trabalho foram elencadas no Quadro 2. Ressalta-se que apenas dois trabalhos concluídos trataram do desenvolvimento de atividades que contemplassem alunos DV (T2 e T3), e ambos carecem de testes.

T2 teve como resultado uma alternativa para a identificação de funções orgânicas a partir de um modelo de geometria molecular com agentes odorantes e texturas. Possui trechos que se mostram contrários a inclusão escolar e não aprofunda a questão de como o olfato pode ser explorado, visto que se trata de um sentido pouco aproveitado neste contexto.

Quadro 7: Potencialidades e Fragilidades identificadas no corpus de análise

\begin{tabular}{|c|c|c|}
\hline & Potencialidades & Fragilidades \\
\hline 1 & $\begin{array}{l}\text { Identificou a partir de uma revisão bibliográfica } \\
\text { propostas que permitissem trabalhar química } \\
\text { orgânica com alunos DV de maneira inclusiva, e a } \\
\text { possibilidade de desenvolver materiais didáticos } \\
\text { utilizando recursos simples, como palitos de } \\
\text { fósforos e barbante. Ressaltou a necessidade de que } \\
\text { sejam desenvolvidos novos trabalhos que explorem } \\
\text { esse tema. }\end{array}$ & \\
\hline 2 & $\begin{array}{l}\text { Desenvolvimento de um modelo de geometria } \\
\text { molecular adaptado com agentes odorantes, ou } \\
\text { seja, a proposta estava pautada em uma abordagem } \\
\text { multissensorial a partir de recursos simples e de } \\
\text { baixo custo, sendo acessível para os professores. }\end{array}$ & $\begin{array}{l}\text { Não deixa claro em que contexto e como a } \\
\text { proposta deve ser aplicada, atentando-se } \\
\text { apenas a construção de um modelo molecular } \\
\text { adaptado. Não fornece informações sobre a } \\
\text { escolha das quatro funções orgânicas } \\
\text { apresentadas (éter, amina, álcool e aldeído), } \\
\text { assim como sua associação com cada aroma } \\
\text { utilizado. Propõe que o trabalho seja testado } \\
\text { apenas com alunos DV, utilizando mapas }\end{array}$ \\
\hline
\end{tabular}




\begin{tabular}{|c|c|c|}
\hline & & $\begin{array}{l}\text { conceituais em Braille, ou seja, difere-se da } \\
\text { proposta de inclusão em que todos os alunos } \\
\text { devem trabalhar em conjunto. Além disso, o } \\
\text { trabalho também apresenta colocações que } \\
\text { diferem da ideia de inclusão escolar. Carece de } \\
\text { testes que permitam avaliar a viabilidade de } \\
\text { seu uso em contextos reais. }\end{array}$ \\
\hline 3 & $\begin{array}{l}\text { Desenvolvimento de material didático acessível a } \\
\text { alunos DV, para o ensino de bioquímica. Preocupa- } \\
\text { se em desenvolver uma abordagem que propicie a } \\
\text { formação crítica e a alfabetização científica dos } \\
\text { alunos. A primeira etapa consiste de um } \\
\text { experimento simples que permite compreender } \\
\text { como se dá o processo de respiração. A última } \\
\text { etapa procura desenvolver roteiros de estudo em } \\
\text { formato podcast, permitindo reforçar a partir da } \\
\text { audição os conteúdos abordados }\end{array}$ & $\begin{array}{l}\text { O trabalho não foi testado, e por isso em sua } \\
\text { segunda etapa ao propor a realização da } \\
\text { exposição de conceitos utilizando o projetor } \\
\text { pode apresentar dificuldades visto que alguns } \\
\text { significados podem ser indissociáveis de } \\
\text { representações visuais. Neste sentido, exige um } \\
\text { grande nível de detalhamento oral para que } \\
\text { essas informações sejam acessíveis aos alunos } \\
\text { DV. }\end{array}$ \\
\hline 4 & $\begin{array}{l}\text { Permitiu a partir de relatos de deficientes visuais e } \\
\text { professores evidenciar como ensino de química } \\
\text { vem sendo realizado nas escolas do Brasil. } \\
\text { Evidenciou a importância de fornecer condições } \\
\text { adequadas para que o ensino seja realizado, assim } \\
\text { como a formação continuada dos professores. }\end{array}$ & \\
\hline 5 & $\begin{array}{l}\text { Permitiu a partir das percepções de professores de } \\
\text { química compreender os conceitos considerados } \\
\text { mais difíceis para o ensino de alunos DV, e a } \\
\text { identificação de um distanciamento da educação } \\
\text { básica e pesquisas científicas voltadas ao ensino. } \\
\text { Ressaltou a importância da formação docente, e } \\
\text { poderá orientar o desenvolvimento de novas } \\
\text { pesquisas voltadas para o desenvolvimento de } \\
\text { métodos e metodologias acessíveis a alunos DV. }\end{array}$ & $\vec{\square}$ \\
\hline$\Theta V$ & $\begin{array}{l}\text { Consiste em um projeto inovador e diferenciado } \\
\text { por aliar o ensino de química com a literatura } \\
\text { popular. Neste sentido, propõe abordar conceitos } \\
\text { científicos em um contexto multidisciplinar, } \\
\text { utilizando materiais de apoio com caráter } \\
\text { multissensorial. }\end{array}$ & \\
\hline 7 & $\begin{array}{l}\text { Permitiu através de relatos de deficientes visuais } \\
\text { constatar o descumprimento de políticas públicas } \\
\text { no que se refere a educação especial. Evidenciou a } \\
\text { importância da formação docente para que não se } \\
\text { perpetuem visões deformadas da ciência, } \\
\text { despertando maior interesse dos alunos. }\end{array}$ & \\
\hline
\end{tabular}

\section{CONCLUSÕES}

A presente pesquisa teve como objetivo analisar as percepções de inclusão em trabalhos desenvolvidos com foco no ensino de alunos DV. Para isso foram criadas categorias, as quais evidenciaram como cada um dos trabalhos tratava pontos importantes no processo de inclusão. 
Edição Especial: I SSAPEC - Simpósio Sul-Americano de Pesquisa em Ensino de Ciências ISSN: 2595- $4520 \quad$ Vol. 4, n. 3. 2021

Os estudos teóricos como T4 e T7 que permitiram a partir de relatos de deficientes visuais compreender quais são as reais demandas para promover a aprendizagem e o interesse dos alunos DV em aulas de Química. Além disso, evidenciou falhas no cumprimento de políticas públicas e na formação de docentes, o que prejudica o processo de inclusão.

T5 investigou a percepção de professores de química atuantes e em formação inicial. As atitudes e percepções dos docentes configuram-se como uma das principais barreiras para a promoção da inclusão, e, portanto, o estudo mostra-se muito relevante. O mesmo evidenciou conceitos considerados difíceis pelos professores, apontando direções para novas pesquisas.

A análise das percepções de inclusão presente em cada um dos trabalhos foi realizada a partir de categorias, as quais buscaram evidenciar como cada um dos trabalhos tratava pontos importantes no processo de inclusão: a capacidade do aluno DV aprender conceitos químicos; o desenvolvimento cognitivo de alunos DV e sua relação com os sentidos sensoriais; a compensação por outros sentidos; a mediação social; a importância da formação de professores; o uso de recursos alternativos de apoio; e as principais dificuldades para que a inclusão possa ser efetivada.

Apenas três das pesquisas analisadas tratavam do desenvolvimento de atividades para alunos DV em uma perspectiva inclusiva, sendo que uma ainda está em desenvolvimento. Dentre estas propostas, T2 mostrou-se como um trabalho que carece de diversas melhorias, apesar de se mostrar diferenciado ao utilizar o olfato em contextos de aprendizagem. O trabalho não deixa claro o motivo de escolher cada uma das funções e seus odores relacionados, assim como o contexto em que deveria ser aplicado.

Pode-se constatar uma existente lacuna no que se refere ao ensino de química para alunos com deficiência visual em uma perspectiva inclusiva, e considera-se importante que mais pesquisas sejam desenvolvidas na Universidade Federal de São Carlos, Campus Araras, visando abranger a diversidade presente em sala de aula. Ressalta-se a importância de que estas pesquisas sejam aplicadas em contextos reais, aproximando a pesquisa científica da educação básica brasileira.

\section{REFERÊNCIAS}


BICHOFF, N.L.C. Revisão bibliográfica sobre metodologias utilizadas para ensinar conceitos de química orgânica para alunos com deficiência visual. Trabalho de conclusão curso. UFSCar. Araras. 2017.

CAMARGO, E.P. Saberes docentes para a inclusão do aluno com deficiência visual em aulas de Física. 1. ed. São Paulo: Unesp, 2012. v 1. 260p.

CARVALHO, R. E. Educação Inclusiva: com os pingos no “is". 8. ed. Porto Alegre: Editora Mediação, 2011.

LAGE, M.C. Utilização do software NVivo e m pesquisa qualitativa: uma experiência em EaD. ETD - Educação Temática. Digital, Campinas, v.12, n.esp., p.198-226, mar. 2011.

MITTLER, P. Educação inclusiva: contextos sociais. 1.ed. Porto Alegre: Artmed, 2003. 265 p.

MOLENA, J.C. O processo de aprendizagem de conceitos químicos por alunos com deficiência visual. Projeto de Mestrado, UFSCar, 2017

MORAES, R.; GALIAZZI, M.C. Análise Textual Discursiva. 3.ed. Ijuí: Ed. Unijuí, 2016, 264p.

REATO, E. Substâncias odorantes como auxiliares na identificação de grupos funcionais orgânicos: uma proposta de ensino de química para alunos com deficiência visual. Trabalho de conclusão curso. UFSCar. Araras. 2017.

SANTOS, M.B. Ensino de Química e a trajetória escolar de deficientes visuais: dificuldades e desafios. Trabalho de Conclusão de Curso de graduação em Licenciatura em Química. Araras. UFSCar. 2018a.

SANTOS, M.B. A Química na perspectiva de adultos cegos do centro dia de referência de atendimento para pessoas com deficiência de Rio Claro. Iniciação Científica. Araras. UFSCar. 2018b.

SANTOS, M.B. Ensino de química e Literatura de Cordel: desenvolvimento e aplicação de livro paradidático sobre química orgânica para alunos deficientes visuais. Mestrado em Educação em Ciências e Matemática (em andamento). Araras. UFSCar. 2019.

VERASZTO, E.V.; CAMARGO, E.P.; CAMARGO, J.T.F. A visão como requisito para conhecimento de fenômenos físicos: um estudo da opinião de licenciandos. In: Encontro de Física 2016, XVI EPEF, 2016 Natal. Anais... Natal-RN, 2016.

VERASZTO, E. V. et al. Professores em formação em Ciências da Natureza: Um estudo acerca da atuação de cegos congênitos em atividades científicas. Formação Docente, v. 06, p. 69-86, 2014. 
Edição Especial: I SSAPEC - Simpósio Sul-Americano de Pesquisa em Ensino de Ciências

VERASZTO, E.V. et al. Blindness and science conceptualization. ETD - Educação Temática Digital, [s.l.], v. 21, n. 2, p.435-458, 30 abr. 2019. Universidade Estadual de Campinas.

VERASZTO, E.V. et al. Evaluation of concepts regarding the construction of scientific knowledge by the congenitally blind: an approach using the Correspondence Analysis method. Ciência \& Educação, [s.1.], v. 24, n. 4, p.837-857, dez. 2018a. FapUNIFESP (SciELO).

VERASZTO, E. V. et al. Conceitualização em ciências por cegos congênitos: um estudo com professores e alunos do ensino médio regular. Revista Electrónica de Enseñanza de las Ciencias, v. 17, n. 3, p. 540-563, 2018 b.

VIGOTSKI, L.S. Obras Escogidas: V Fundamentos de Defectologia. Editora Aprendizaje Visor. $2^{\mathrm{a}}$ ed. Madrid, 1997, p.391.

VIVEROS, E. de; CAMARGO, E. P. de. Deficiência visual e educação científica: orientações didáticas com um aporte na neurociência cognitiva e teoria dos campos conceituais. Góndola, Bogotá, v. 6, n. 2, p. 25-50, dez/2011.

ZAMBONE, C.S. Proposta de material didático acessível para o ensino de bioquímica a alunos com deficiência visual. Trabalho de conclusão curso. UFSCar. Araras. 2017. 